\title{
Gastric Glomus Tumor: A Case Report
}

Gio Earnest de la Cruz, ${ }^{1}$ Carolyn Marie Legaspi, ${ }^{1}$ Jose Carnate, Jr. ${ }^{1,2}$

${ }^{1}$ Department of Laboratory Medicine and Pathology, The Medical City, Pasig City, Philippines

${ }^{2}$ Department of Pathology, College of Medicine, University of the Philippines Manila

\section{ABSTRACT}

Glomus tumor is an uncommon mesenchymal neoplasm usually described in the distal extremities, and

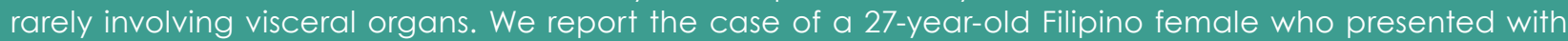
episodes of dizziness and weakness, associated with a low hemoglobin count. Further work-up showed a $5.5 \mathrm{~cm}$ submucosal gastric mass, which was demonstrated on microscopic and immunohistochemical studies to be a gastric glomus tumor (GGT). Although rare, GGTs should be part of the differential diagnoses of submucosal gastric masses.

Key words: glomus tumor, stomach neoplasms, immunohistochemistry

ISSN 2507-8364 (Online)

Printed in the Philippines.

Copyright $($ C) 2021 by the PJP.

Received: 28 October 2021.

Accepted: 2 December 2021.

Published online first: 9 December 2021.

https://doi.org/10.21141/PJP.2021.17

Corresponding author: Gio Earnest D. de la Cruz, MD, MBA

E-mail: gioeddelacruz@gmail.com

ORCiD: https://orcid.org/0000-0003-2589-850x

\section{INTRODUCTION}

Gastric glomus tumor (GGTs) is a rare mesenchymal neoplasm mainly arising within the submucosa of the gastric antrum. It commonly presents with epigastric discomfort or upper gastrointestinal bleeding symptoms, ${ }^{1}$ and diagnosis is based on histologic examination, supported with immunohistochemical studies. ${ }^{2}$ Glomus tumors are more commonly described in the extremities, and rarely seen in other organs. This case is a 27-year-old Filipino female with a history of low hemoglobin levels and a submucosal gastric mass on imaging.

\section{CASE}

A 27-year-old Filipino female consulted at the emergency department for episodes of dizziness and weakness which started a week prior. Upon workup, her hemoglobin levels were low at $39 \mathrm{~g} / \mathrm{dL}$, prompting transfusion of three units of packed red blood cells. She was eventually discharged stable. An abdominal CT scan with contrast was performed on an outpatient basis, which revealed a $6.3 \times 4.5 \times 5.2 \mathrm{~cm}$ hypodense mass involving the wall and lumen of the gastric pyloantral region and the $1^{\text {st }}$ and $2^{\text {nd }}$ segments of the duodenum, with luminal narrowing, as shown in Figure 1. Considerations at this point were gastrointestinal stromal tumor, adenocarcinoma, lymphoma, and hemangioma, and the patient underwent surgical procedure. No preoperative biopsy was performed.

A partial gastrectomy specimen was received from the antrum, and further opening revealed a well-defined, $5.5 \times 3.7 \mathrm{~cm}$ intramural mass, with a dark red, soft to hemorrhagic cut surface. It narrows the lumen but does not completely obstruct it. The overlying mucosa is not ulcerated, and the serosa was smooth on gross examination. Microscopic examination of the mass as shown in Figure 2 showed nests and cords of monomorphic small round cells with sharp borders, arranged around dilated sinusoidal blood vessels. The individual cells had uniform round nuclei with focal mild atypia, fine chromatin, conspicuous nucleoli, and fairly moderate amounts of eosinophilic cytoplasm. Mitotic count was at 1-2 per 50 high power fields. No areas of necrosis were seen. Lymphovascular 


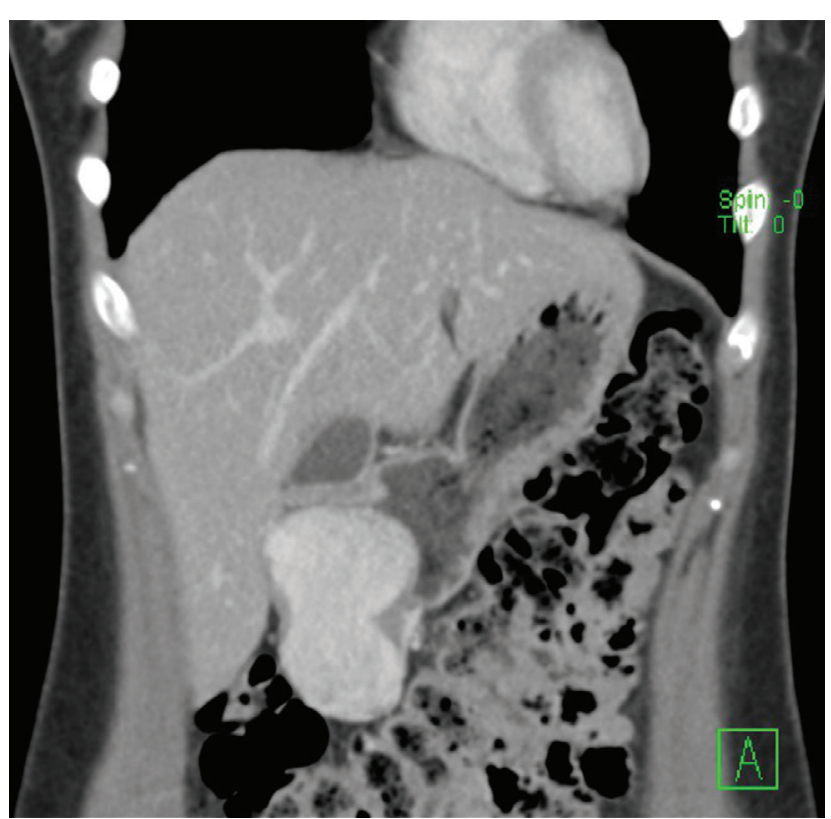

Figure 1. Coronal CT scan image of the enhancing, submucosal gastric mass.
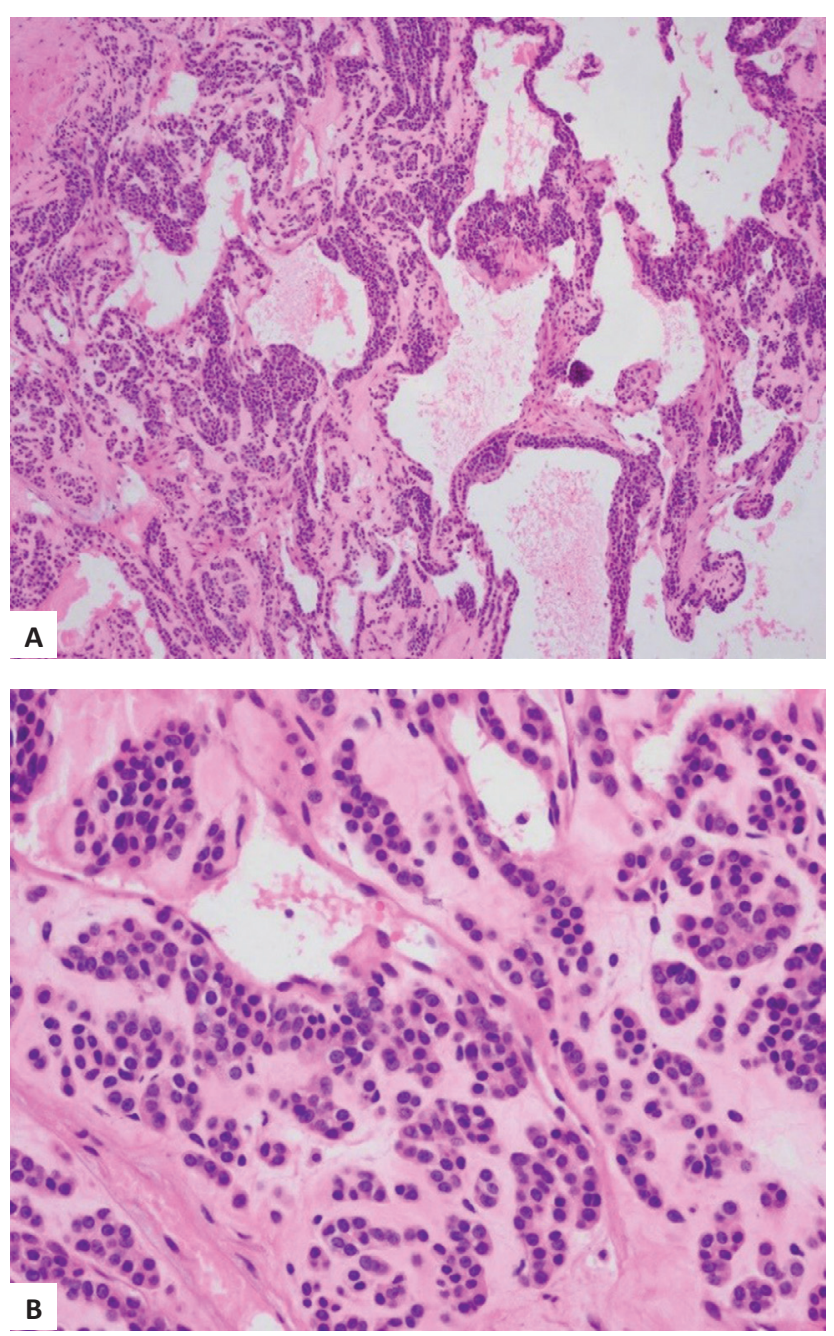

Figure 2. Microscopic images of the gastric tumor, which discloses nests of monotonous round cells arranged around dilated blood vessels (A) H\&E, 100x, (B) H\&E, 400x. space invasion and focal visceral peritoneal involvement were identified. Immunohistochemical studies showed the tumor was positive for muscle-specific actin (MSA), smooth muscle actin (SMA), and vimentin, as shown in Figure 3. It was focally and weakly positive for synaptophysin and CD56, and negative for Cam 5.2, CK, LCA, CD34, chromogranin, c-kit, and Ki-67. Caldesmon was not available at the institution.
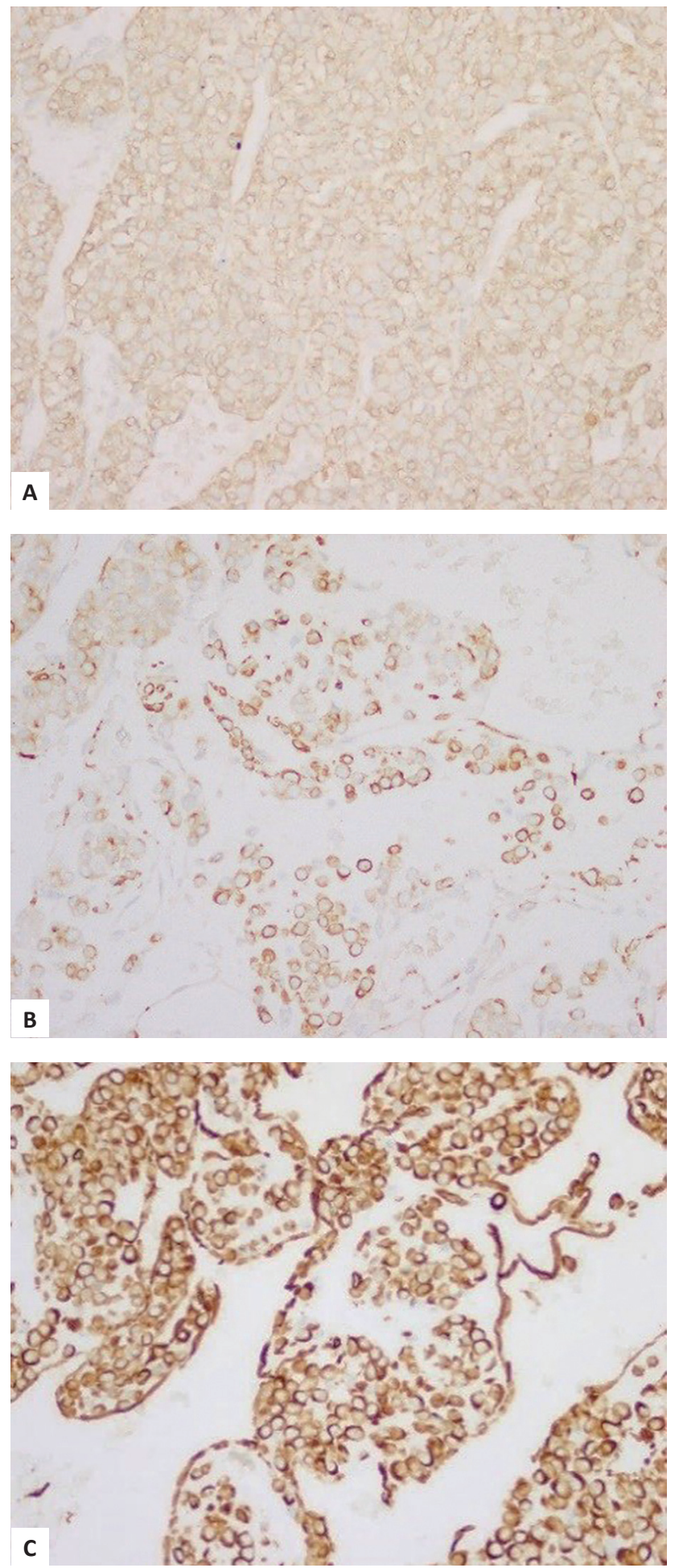

Figure 3. The tumor is positive for (A) SMA, (B) MSA, and (C) vimentin immunohistochemistry, 400x. 


\section{DISCUSSION}

Glomus tumors are rare lesions that account for less than $2 \%$ of soft tissue tumors. They are of mesenchymal origin that resemble the perivascular modified smooth muscle cells of the normal glomus body. They mostly occur in the distal extremities, and rarely in other sites. ${ }^{3}$ In the gastrointestinal tract, they almost always arise in the stomach, in particular the antrum. ${ }^{1}$ They are much rarer than other mesenchymal tumors in the stomach, accounting for approximately $1 \%$ of gastric mesenchymal tumors. ${ }^{2,4,5}$ In the stomach, glomus tumors have a strong female predominance, and may occur at any age, with a median age of 55 years (range 19-90 years). It usually presents with symptoms of upper gastrointestinal bleeding, epigastric pain, and on occasion, obstructive symptoms. ${ }^{1}$ In our case, the patient's symptoms and low hemoglobin count was likely due to blood loss caused by the gastric glomus tumor.

Implicated in the pathogenesis of gastric glomus tumors are the NOTCH family of genes in sporadic cases, inactivating mutations in the glomulin gene $(G L M N)$ in multiple familial glomus tumors, and $B R A F$ mutations in a minority of cases. ${ }^{1}$

Gastric glomus tumors are often well-circumscribed and intramural in location ${ }^{1}$, and imaging studies are usually unable to differentiate glomus tumors from other mesenchymal tumors in the stomach. ${ }^{5,6}$ Hence, diagnosis relies on microscopic examination and immunohistochemical studies. Histologically, the tumor consists of a monotonous population of small round cells with distinct borders, central dark and round nuclei, and moderate amounts of eosinophilic to clear cytoplasm. The cells are in nests and clusters, arranged around dilated blood vessels. The stroma is focally myxoid or hyalinized., Mitotic activity is usually low, but it may have focal nuclear atypia and vascular invasion, the latter of which is not associated with an adverse prognosis. It strongly expresses SMA in virtually all cases, and may also express caldesmon, collagen IV, laminin, and vimentin. ${ }^{1,2}$ Although caldesmon was not performed in this case due to its unavailability in the institution, the authors felt the combined sensitivity of SMA and MSA was sufficient in confirming a smooth muscle lineage. A strong SMA expression is in fact a desirable diagnostic criterion of this tumor. ${ }^{1}$ Synaptophysin may be expressed focally but are usually negative for other neuroendocrine markers. It is also negative for desmin, S100, keratin, CD34, KIT, and DOG1. GGTs are similar morphologically and immunohistochemically to glomus tumors of other sites. ${ }^{1}$

The morphologic differential diagnoses of GGT include neuroendocrine tumors, epithelioid gastrointestinal stromal tumor (GIST), paraganglioma, hemangiopericytoma, and lymphoma. Neuroendocrine tumors also consist of a uniform population of small round cells but have relatively coarse chromatin and scant cytoplasm. These also express keratins and multiple neuroendocrine markers, but SMA is negative. ${ }^{5}$ Epithelioid GIST may also have cells that contain eosinophilic to clear cytoplasm, which can look like GGTs with epithelioid morphology. The stroma is not typically rich in vessels in GIST, however. GIST strongly expresses CD117, DOG-1, and CD34, and only focally express SMA. On the other hand, GGTs are consistently negative for CD117.,5 Paragangliomas, although less common in the stomach, may also mimic a glomus tumor. They are, however, strongly positive for synaptophysin and chromogranin, and negative for SMA. ${ }^{5}$ Hemangiopericytomas, like GGT, also show dilated blood vessels, but the former has angulated and branching vessels. These tumors are negative for smooth muscle markers, and positive for CD34. ${ }^{7}$ Lymphomas may also be difficult to distinguish morphologically from GGT, especially on frozen sections. Immunohistochemistry can easily resolve this $;^{7}$ GGTs are usually negative for CD20 and CD45. ${ }^{5}$

Most GGTs are benign, and definitive treatment is through complete excision of the tumor by wedge or segmental resection or partial gastrectomy. The criteria for malignancy in GGTs remain undefined due to insufficient large-scale studies. The usual variables used in determining malignancy for peripheral soft tissue tumors include a deep location and size $>2 \mathrm{~cm}$, presence of atypical mitotic figures, and presence of moderate to high nuclear grade and $\geq 5$ mitoses/ $10 \mathrm{~mm}^{2} .{ }^{1}$ However, other studies propose this as unsuitable for GGTs, as most of these tumors grow larger than $2 \mathrm{~cm},,^{2,4,5}$ and even tumors with low mitotic counts can occasionally metastasize, especially those of a larger size $(>5 \mathrm{~cm}){ }^{5,8}$

\section{SUMMARY AND CONCLUSION}

GGTs are among the rarer neoplasms that may arise from the stomach. Symptoms and radiologic findings may be nonspecific, and diagnosis is made on the histologic examination, supported by immunohistochemical studies. They are often benign, and complete excision is usually the definitive treatment. Despite its rarity, they should be included in the differential diagnoses of patients presenting with upper gastrointestinal bleeding symptoms.

\section{ETHICAL CONSIDERATIONS}

This case report was submitted to and acknowledged by the Institutional Review Board of The Medical City.

\section{STATEMENT OF AUTHORSHIP}

All authors certified fulfillment of ICMJE authorship criteria.

\section{AUTHOR DISCLOSURE}

The authors declare no conflict of interest.

\section{FUNDING SOURCE}

None. 


\section{REFERENCES}

1. Glomus Tumor. In: WHO Classification of Tumours: Digestive System Tumours. 5th ed., vol. 1. IARC: Lyon; 2019.

2. Wang ZB, Yuan J, Shi HY. Features of gastric glomus tumor: a clinicopathologic, immunohistochemical and molecular retrospective study. Int J Clin Exp Pathol. 2014;7(4):1438-48. PMID: 24817939. PMCID: PMC4014223.

3. Glomus Tumor. In: WHO Classification of Tumours: Soft Tissue and Bone Tumours. 5th ed., vol. 3. IARC: Lyon; 2020.

4. Miettinen M, Paal E, Lasota J, Sobin LH. Gastrointestinal glomus tumors: a clinicopathologic, immunohistochemical, and molecular genetic study of 32 cases. Am J Surg Pathol 2002:26(3):301-11. PMID: 11859201. https://doi.org/10.1097/00000478200203000-00003.
5. Wang X, Hanif S, Wang B, Cai C. Management of gastric glomus tumor: a case report. Medicine (Baltimore). 2019; 98(38):e16980. PMID: 31567933. PMCID: PMC6756591. https://doi.org/10.1097/MD. 0000000000016980.

6. Nascimiento EFR, Fonte FP, Mendonça RL, Nonose $\mathrm{R}$, de Souza CAF, Martinez CAR. Glomus tumor of the stomach: a rare cause of upper gastrointestinal bleeding. Case Rep Surg. 2011;2011:371082. PMID: 22606576. PMCID: PMC3350055. https://doi.org/ $10.1155 / 2011 / 371082$.

7. Lin J, Shen J, Yue H, Li Q, Cheng Y, Zhou M. Gastric glomus tumor: a clinicopathologic and immunohistochemical study of 21 cases. BioMed Res Int. 2020;2020:5637893. PMID: 32337257. PMCID: PMC7157787. https://doi.org/10.1155/2020/5637893.

8. Lee H, Lee JJ, Yang DH, Lee BH. A clinicopathologic study of glomus tumor of the stomach. J Clin Gastroenterol. 2006;40(8):717-20. PMID: 16940885. https://doi.org/10.1097/00004836-200609000-00011.

\footnotetext{
Disclaimer: This journal is OPEN ACCESS, providing immediate access to its content on the principle that making research freely available to the public supports a greater global exchange of knowledge. As a requirement for submission to the PJP, all authors have accomplished an AUTHOR FORM, which declares that the ICMJE criteria for authorship have been met by each author listed, that the article represents original material, has not been published, accepted for publication in other journals, or concurrently submitted to other journals, and that all funding and conflicts of interest have been declared. Consent forms have been secured for the publication of information about patients or cases; otherwise, authors have declared that all means have been exhausted for securing consent.
}

\section{Publish in the new PJP. Visit our website:} http://philippinejournalofpathology.org 